Revista Iberoamericana, Vol. LXXVI, Núm. 231, Abril-Junio 2010, 295-303

\title{
A LOS MÁRGENES: HACIA UNA DEFINICIÓN DE “NEGRA”
}

POR

\author{
William J. NichOLS \\ Georgia State University
}

El término “negra” de "novela negra” con frecuencia provoca confusión debido a los múltiples niveles semánticos de la palabra y a su asociación con tendencias artísticas y literarias específicas dentro de la cultura hispánica. ¿Qué, por ejemplo, podría conectar la estética de la "novela negra" con la llamada "pintura negra" de Goya, donde las imágenes de caras deformadas y cuerpos descompuestos, temas de brujería y canibalismo, y cuestiones de sufrimiento y desesperación desvelan una humanidad monstruosa que padece las consecuencias de los ideales fracasados de la Ilustración? Tal vez, la "novela negra" comparta una conexión más íntima con el pesimismo y la oscuridad de la visión romántica ejemplificada por autores tales como el Duque de Rivas, Martínez de la Rosa y Espronceda, o incluso los escritos pre-románticos de José Cadalso y Jovellanos. No obstante, ¿podría poseer la “novela negra” algo en común con la oscuridad tenebrosa del naturalismo de Pardo Bazán, donde las intenciones escondidas y las tendencias primitivas comunican un mundo misterioso, más allá del control de cualquier individuo? ¿Podría la palabra "negra” revelar alguna relación con los tonos negros y grises de la "Guernica” de Picasso, que evoca las sombras bajo las columnas de humo y la verdad descuartizada en las penumbras del discurso oficial?

Irónicamente, la "negra” de la llamada “novela negra” no conlleva una herencia directa con ninguna de estas visiones oscuras de la cultura hispana, sino que representa una asimilación al contexto hispano de la ficción criminal de denominación noir que tiene su principio en los años 20 en Norteamérica. Si una indagación sobre el significado de negra nos conduce a noir, entonces, ¿qué significa exactamente noir? ¿Es noir un género que obedece a ciertas convenciones específicas con relación a medios concretos tales como novela, cine, o cómic? ¿Es necesariamente una expresión "baja” de la cultura popular o puede haberse infiltrado lo noir en los espacios cerrados del canón? ¿Es noir un movimiento artístico que florece dentro de un marco temporal específico, o se encuentran ejemplos de una estética noir antes 
del momento histórico típicamente considerado como su nacimiento? ¿Persiste esta estética noir hasta hoy en día? De igual forma, ¿̇se limita la producción de lo noir geográfica y culturalmente al contexto norteamericano? ¿Cuál es la diferencia entre noir y el llamado hard-boiled ("novela dura”)? ¿Es noir lo mismo que la ficción detectivesca y viceversa? Mientras se dirige a estas preguntas, el concepto de noir, o negra, se definirá más bien en términos de su visión como una "poética" en vez de una lista de características estilísticas o genéricas. La idea de novela negra en la literatura hispana evocará, además, una afinidad más fuerte con las nociones, críticas y preocupaciones de aquellas otras formas de producción artísticas dentro de la cultura hispana mencionadas arriba.

El título de esta introducción recuerda el ensayo clave de Raymond Borde y Étienne Chaumeton de 1955, titulado "Towards a Definition of Film Noir" ("Hacia una definición de cine negro") en el cual los autores franceses intentan clasificar las películas de Norteamérica que aparecieron en Francia durante los años 40. Borde y Chaumeton asocian una producción estética noir estrictamente con el cine y notan vínculos temáticos, estilísticos, e incluso existenciales entre filmes como Maltese Falcon de Huston, The Big Sleep de Howard Hawk, Murder, My Sweet de Edward Dmytryk, y Double Indemnity de Billy Wilder. Estos autores atribuyeron el título noir a las películas señaladas porque proyectaban una mirada oscura de la sociedad moderna, donde el crimen y la violencia habían borrado la distinción moral entre el bien y el mal (21). Según Borde y Chaumeton, el abuso y el homicidio, la perversión y depravación sexual, la ansiedad y la ambigüedad matizan la existencia de una humanidad alienada. Con una visión fatalista, los individuos en estas películas caen presas de un mal endémico, en un sistema y una sociedad donde los valores de la democracia, la ley, el orden y la justicia se han desmoronado.

Aunque Borde y Chaumeton se enfocan exclusivamente en el cine norteamericano, son los primeros en establecer un entendimiento de lo que constituye lo noir, un concepto que otros expandirán y que se podrá aplicar a otras formas artísticas además del cine. Raymond Durgnat, en su ensayo de 1970, "Paint It Black: The Family Tree of the Film Noir", ${ }^{1}$ sigue dentro del contexto cinemático erigido por Borde y Chaumeton, pero forja una discusión sobre lo noir basada en lo que él llama "motif and tone" (38) ("tema y tono") en vez de género, donde los temas de desafecto y angustia, declara, "evoke classic tragic spirit” (37) (evocan un espíritu trágico clásico) dentro de un contexto específicamente norteamericano. Durgnat vincula el cine negro con las tragedias griegas como Oedipus Rex y con

1 Las referencias a este artículo son de la reimpresión del texto encontrada en Film Noir Reader, páginas 37-51 de Silver. El artículo de Durgnat también se encuentra en otras fuentes como The Big Book of Noir editado por Ed Gorman, Lee Server, y Martin H. Greenberg.

Revista Iberoamericana, Vol. LXXVI, Núm. 231, Abril-Junio 2010, 295-303
ISSN 2154-4794 (Electrónico) 
mitos como los de Climenestra y Eurípides, mientras que categoriza lo noir al lado de los black classics (37) (“clásicos negros”) de otros escritores como Dostoievsky, Faulkner y Lautréaumont. Sugiere Durgnat, además, sin explorarlo abiertamente, que lo noir se extiende más allá del medio del cine, de los límites del tiempo y de las fronteras culturales al evocar una visión negra de la sociedad moderna.

Paul Schrader, en "Notes on Film Noir”, adelanta la exploración del cine negro empezado por Durgnat, Borde y Chautemon al concebirlo no como un género determinado por "the conventions of setting and conflict (53)" (las convenciones de entorno y conflicto) como son los géneros de vaqueros y gángsters, sino al definirlo en términos de tono, tema y ambiente. Schrader enumera catalizadores sociales, influencias cinemáticas y precedentes literarios que contribuyen al estilo del cine negro que, a su vez, comunica una visión de futilidad, desesperación y pesimismo. Al contrario de las películas propagandísticas cuyo propósito era levantar la moral de la población y generar optimismo durante la Segunda Guerra Mundial, Schrader afirma que la desilusión de la posguerra estimuló la producción de cine negro y su realismo brutal (54). Cinematográficamente, las técnicas utilizadas por los directores noir para evocar la ansiedad en los espectadores y connotar la ambigüedad moral (las dos características principales del cine negro según Borde y Chaumeton) se derivaron directamente de la influencia de los expresionistas alemanes, tales como Fritz Lang, Robert Siodmak, Billy Wilder y Otto Premminger (55). Las luces tenues, las calles alumbradas de noche, los faroles solitarios con figuras escondidas en las sombras, los ángulos extraños de luz que contrastan con la oscuridad para provocar chocantes formas y efectos ópticos, junto con otras técnicas, recuerdan las películas expresionistas del cine mudo alemán, como El gabinete del Dr. Caligari. El uso de estas convenciones cinematográficas tenía el propósito de articular el sentimiento de pérdida, nostalgia, incertidumbre y fatalismo típico de la visión noir. Si los directores expatriados alemanes aportan al cine negro un estilo visual, entonces, declara Schrader, la tradición "dura” o "hard-boiled" de autores como Hammett, Hemingway, Chandler, Cain y McCoy ofrecen la inspiración y la influencia de los guiones del cine negro (56). Schrader, como Durgnat, expande el concepto de noir para incorporar un entendimiento de estilo y escritura como un medio para comunicar una visión oscura de la sociedad que persistía en los Estados Unidos después de la Segunda Guerra Mundial. Como consecuencia, Durgnat y Schrader abren el camino para otros críticos que amplían las nociones de noir más allá del cine y lo discuten como un ideal crítico que se aproxima al nivel de mito, puesto que no está restringido por la historia, la cultura o la forma.

En su libro Voices in the Dark: The Narrative Patterns of Film Noir (1989), J.P. Telotte analiza la estructura narrativa y las estrategias discursivas del llamado cine negro, pero sus conclusiones le conducen a entender lo noir como una forma particular de un discurso cultural mítico más allá del cine:

Revista Iberoamericana, Vol. LXXVI, Núm. 231, Abril-Junio 2010, 293-303
ISSN 2154-4794 (Electrónico) 
We shall see it as a symptom, a distortion that cuts across generic lines and that is caused by the same desires and powers that propel our culture and our lives. But whether viewed as a response to distortion or as itself a stylistic and thematic distortion that infects our prevailing cultural myths [...] the film noir can designate a field of deviation that mirrors the problems of modern America in particular and modern man in general. (11)

[Lo veremos como un síntoma, una distorsión que cruza las fronteras genéricas y que es causado por los mismos deseos y poderes que impulsan nuestra cultura y nuestras vidas. Pero si es visto como una respuesta a la distorsión o una distorsión estilística y temática en sí que infecta nuestros mitos culturales más prevalecientes [...] el cine negro puede designar un campo de desviación que refleja los problemas de América moderna en particular y del ser humano moderno en general.]

Al entender lo noir como una forma de discurso que articula un entendimiento específico y una visión concreta del mundo, Telotte traslada la discusión de la definición de noir de las consideraciones de estilo y forma al campo de las ideas y de los mitos que cualquier persona o cultura pueda verbalizar.

Geoffrey O’Brien corrobora el entendimiento mítico de lo noir de Telotte, pero se enfoca en la producción de ficción, en vez de cine, en su libro Hardboiled America: Lurid Paperbacks and Masters of Noir (1997). O’Brien reconoce los elementos de lo noir y de lo hard-boiled en muchos ejemplos de la literatura norteamericana, pero propone a Dashiell Hammett como una figura catalizadora que une las características estéticas con los valores míticos pero participando en una forma literaria; así están las llamadas revistas pulp, que, por su medio de producción, infunden lo noir en la lucha de clases. El bajo costo y el tamaño compacto de las revistas, afirma O’Brien, no sólo facilita la circulación de los textos por las clases obreras, sino que también imita el ritmo acelerado de las tramas y los diálogos de muchos de los cuentos (8). ${ }^{2}$ Además, las portadas de las revistas y las novelas pulp solidifican visualmente los mitos articulados en los textos con imágenes icónicas que representan las luchas crueles "in much the same sense that medieval art might be said to consist of illustrations of the Bible, and much Renaissance and Baroque art of illustrations of classical mythology" (61) [en el mismo sentido que el arte medieval se podría contemplar como ilustraciones de la Biblia, y mucho del arte renacentista y barroco como ilustración de la mitología clásica”]. Para O’Brien, lo noir como una mitología moderna empezó con la primera publicación de Hammett en la famosa revista Black Mask en 1922, lo cual transformó una visión

2 Michael Denning examina la conexión entre clase social y el desarrollo de los libros de portada blanda durante el siglo diecinueve en Mechanic Accents: Dime Novels and Working-Class Culture in America. Luego, Erin A. Smith se enfoca específicamente en las ideologías de clase en las novelas duras caracterizadas como ficción pulp en Hard-boiled: Workin-Class Readers and Pulp Magazines.

Revista Iberoamericana, Vol. LXXVI, Núm. 231, Abril-Junio 2010, 295-303 ISSN 0034-9631 (Impreso) ISSN 2154-4794 (Electrónico) 
vagamente gótica en una “specifically modern demonology” (62) [una demonología específicamente moderna].

El nihilismo articulado primero ${ }^{3}$ por Hammett se arraigó en otros autores norteamericanos como Raymond Chandler, James M. Cain, Horace McCoy, David Goodis y otros para forjar una poética negra que, según Lee Horsely en The Noir Thrillers $^{4}$ (2001), es la manifestación en la cultura popular de la angustia existencial encontrada en escritores modernistas como Eliot y Conrad (5). Lo noir, como el llamadoAlto Modernismo, ${ }^{5}$ afirma Horsely, representa la reacción a una crisis cultural y ofrece una representación de psiques fragmentadas, individuos alienados, y una frustración general con las promesas fracasadas del “sueño americano”. El enfoque de lo noir en la culpabilidad irresuelta (desde la perspectiva del criminal tanto como del detective) señala en la sociedad una crítica de la culpabilidad individual y social, a la vez que revela un desencanto interno con otras formas artísticas que no logran captar la profundidad de la desesperación. Noir, declara Horsley,

is the "voice of violation", acting to expose the inadequacy of conventional cultural, political and also narrative models. It expresses fear and anxieties but also has the potential for critique, for undermining complacency and illusions (the false promises of the American dream; the hypocrisy of the British establishment). (12)

[es la “voz de violación”, activamente descubriendo la insuficiencia de los modelos convencionales de la cultura, la política y la narrativa. Expresa el miedo y las ansiedades pero también tiene la capacidad de crítica, de subvertir la complacencia y las ilusiones (las promesas falsas del sueño americano; la hipocresía del establecimiento británico).]

La violación y el desencanto, entonces, se encuentran en el corazón de la poética de la novela negra, en el cual lo estético, lo temático y lo mítico se fusionan con lo social y lo histórico en lo que Fredric Jameson ha denominado la "ideology of form” [ideología de la forma] (98).

3 Aunque se acepta a Hammett como el autor que fundó la novela detectivesca dura e impulsó la producción literaria de lo noir, algunos críticos sugieren que otros autores pocos reconocidos, como Carroll John Daly (con su detective neoyorquino Race Williams) y Cornell Woolrich, tenían tanta o más influencia en la fundación del género duro y la visión negra que se articulaba. Al respecto, véase los artículos de Stephen Mertz "In defense of Carroll John Daly”; “The Last Days of Cornell Woolrich” de Barry N. Malzberg y Don Yates y la biografía de Cornell Woolrich de Francis Nevins, titulada First You Dream Then You Die.

4 Un texto similar que trata explícitamente con la noción de los thrillers y al cual Horsely hace referencia es Thrillers, de Martin Rubin.

5 Una aserción similar hace Scott R. Christianson en “A Heap of Broken Images: Hardboiled Detective Fiction and the Discourse(s) of Modernity”.

Revista Iberoamericana, Vol. LXXVI, Núm. 231, Abril-Junio 2010, 293-303 
El concepto de violación y la relación con una modernidad fracasada que destaca Horsley es, por un lado, lo que atrae a los autores del arco latino a la novela negra, pero es, por otro lado, lo que conecta las manifestaciones recientes de novela negra en la cultura hispana con una larga historia de producción cultural que ha criticado las promesas y los fracasos de una modernidad desigual. La estética noir, entonces, ofrece crónicas de la desesperación y la alienación que resultan de los fracasos de la modernidad en los Estados Unidos, desde los años veinte hasta los cuarenta del siglo pasado, ${ }^{6} \mathrm{y}$, en los últimos treinta años, escritores de Latinoamérica y España, además de autores chicanos de los Estados Unidos, han encontrado en la novela negra la posibilidad de ofrecer crónicas de los fracasos de la etapa más reciente de la modernidad: la globalizacón y el neoliberalismo. El discurso político y el realismo social de lo noir resuenan con las "crónicas" de una modernidad desigual en la historia y en la literatura hispana. En la tradición hispana, el discurso literario se ha mostrado como el medio preferido para examinar la realidad social y criticar el proyecto de modernidad y modernización que viene desde hace siglos. Las crónicas del llamado “descubrimiento” en el Nuevo Mundo, por ejemplo, se pueden considerar como la manifestación de un intento de utilizar la escritura para explorar los posibles significados y explicaciones de un mundo antes desconocido, a la vez que la escritura se vuelve un arma clave para imponer orden en las colonias españolas. Durante la época barroca, Sor Juana Inés de la Cruz usa la escritura para subvertir el discurso patriarcal que margina a la voz de la mujer de los procesos no sólo eclesiásticos sino políticos, económicos, e intelectuales también. En los siglos dieciocho y diecinueve, escritores como Carrió de la Vandera, Echeverría, Sarmiento y Lizardi citan las contradicciones en los proyectos políticos, económicos y sociales de América Latina. La escritura latinoamericana en el siglo veinte -especialmente las novelas de escritores como Azuela, Asturias, Carpentier, Fuentes, Vargas Llosa, García Márquez y otros- mezclan ficción e historia para examinar las compenetraciones mutuas de sus discursos respectivos en la formación de la identidad moderna de Latinoamérica.

En España, la lucha para entender y definir la identidad moderna de ese país, igual, se lleva a cabo por medio de la escritura. Una nueva monarquía en 1700 introdujo los ideales franceses de la Ilustración en España cuya compatibilidad con la realidad española y sus contradicciones internas se ven exploradas por escritores como Feijoo, Cadalso, Jovellanos e, incluso, Larra, Martínez de la Rosa

${ }^{6}$ Aunque se suele situar temporalmente la producción de cine negro entre los años veinte y los años cuarenta, hay ejemplos del llamado neo-noir en el cine contemporáneo, donde se ven en películas como Blade Runner, Chinatown, Blood Simple, L.A. Confidential, y otras que se apropian abiertamente a la estética asociada con lo noir. Temáticamente, estas películas continúan la tendencia de ofrecer la crónica de una sociedad plagada de crimen, corrupción y alienación, e indagan las contradicciones de una identidad moderna.

Revista Iberoamericana, Vol. LXXVI, Núm. 231, Abril-Junio 2010, 295-303 ISSN 0034-9631 (Impreso) ISSN 2154-4794 (Electrónico) 
y el Duque de Rivas (en el primer cuarto del siglo diecinueve). Las crisis políticas, las invasiones extranjeras, $y$ las revoluciones internas impulsan a los escritores realistas y naturalistas decimonónicos -Valera, Galdós, Clarín, Pardo Bazán, Blasco Ibáñez y otros- a indagar los problemas y las posibilidades de lograr una república liberal y burguesa en España. Con la derrota de España en la Guerra Hispanoamericana, en 1898, y con las pérdidas de las últimas colonias, escritores como Unamuno, Azorín, Machado, Valle-Inclán y Baroja hacen de la escritura un espacio que explora tanto la encrucijada política y cultural en que se encontraba España al principio del siglo veinte como una posible salida de la "abulia" por medio de una regeneración cultural, a través de las figuras míticas de la literatura española como Don Quijote, El Cid, La Celestina y don Juan. Luego, enfrentándose con las tácticas anti-modernas y represivas de la dictadura de Franco, escritores como Fernández Santos, Sánches Ferlosio, Martín Gaite, Benet, Martín Santos y Goytisolo juegan con las estructuras narrativas para evadir la censura a la vez que subvierten el discurso oficial del régimen.

Si bien se manifiesta una relación estrecha entre la escritura y la historia como una examinación del proyecto de la modernidad en el mundo latino, la novela negra ofrece el vehículo idóneo para explorar las contradicciones de la modernidad en la llamada época de la globalización. En los últimos treinta años, dentro de la lógica económica del neoliberalismo, escritores en el arco latino se han apropiado de la estética y la poética del género negro para llevar a cabo su propia investigación de las contradicciones de la (pos)modernidad en sus países respectivos. El propósito de este número de la Revista Iberoamericana es explorar las varias manifestaciones del género negro que se dan desde el Cono Sur hasta México y el Caribe, pero incorporando también ejemplos de escritores chicanos de los Estados Unidos así como autores peninsulares para ampliar el estudio del género y lograr un acercamiento más global que desvele los puntos de contacto que llegan a articular una crítica común.

Como muestran los contribuidores de este número especial de la Revista Iberoamericana, los autores que adoptan la estética asociada con la novela negra perciben en la estructura hermenéutica de este género un mecanismo para llevar a cabo múltiples investigaciones, tanto literarias como sociales, políticas como psicológicas. La investigación de un detective, para empezar, rige la estructura narrativa, una función que ha cumplido desde que Poe inventó el género detectivesco a mediados del siglo xix, e impulsa y dirige la acción de la novela. No obstante, la lógica y el raciocinio inherentes a la investigación, heredados de las posturas filosóficas de la Ilustración y que tienen como expresión más emblemática a la figura de Sherlock Holmes, chocan con una realidad caótica fabricada por una fusión de poder y capital. Figuras marginadas del poder y que articulan una profunda

Revista Iberoamericana, Vol. LXXVI, Núm. 231, Abril-Junio 2010, 293-303
ISSN 2154-4794 (Electrónico) 
desilusión y un sentimiento de violación en la novela negra apelan a los escritores latinos, quienes indagan sobre cuestiones de crimen, verdad y justicia en sociedades donde los modelos democráticos crecen entrelazados con los preceptos capitalistas. La novela negra les ofrece un espacio a estos escritores, desde donde señalan las inconsistencias y las idiosincrasias de los procesos de modernización donde las víctimas de los crímenes muchas veces son de las clases excluidas o marginadas de la modernidad. Reiterando el famoso dicho de Marshall McLuhan, "el medio es el mensaje”, al adoptar el género negro, los destacados escritores de los artículos a continuación reconocen la escritura, y la cultura en general, como un campo de batalla, ya no escapista, como antes se consideraba al género popular de la novela negra, sino comprometido. No es casualidad que la mayoría de los escritores dedicados a la novela negra en Latinoamérica y España, y los escritores chicanos en los Estados Unidos, sean "hijos del 68". Frente al fracaso de los movimientos revolucionarios de los años sesenta, estos escritores ven en la novela negra una manera de revindicar la literatura comprometida y al redefinir los proyectos sociales de la izquierda dentro del contexto neoliberal. Irónicamente, es la popularidad de la novela negra la que la dota con la capacidad de atacar las contradicciones de la era de la globalización. El éxito de la novela negra aporta al género un lugar privilegiado dentro del mercado, desde donde adquiere una naturaleza híbrida que le permite criticar los valores centrales de la globalización: la liberalización y la privatización, la migración transnacional de personas y capital, el consumismo y la objetivación, el aburguesamiento de los espacios urbanos y la marginalización de las clases obreras, la falsificación por los medios masivos de comunicación y el control de información por las clases dirigentes. Irónicamente, aunque la popularidad del género negro y la percepción de éste como una literatura escapista lo ha marginado históricamente del canon, es esta misma marginalización discursiva que sirve como punto de partida para una investigación interna que explora la identidad textual por medio de la auto-referencialidad, la intertextualidad y la parodia. Al parodiar un género extranjero que durante décadas no encontraba raíz en las sociedades latinas, estos autores destacan irónicamente su propia distancia con la modernidad, también como un modelo extranjero importado, y cuestionan con desconfianza la narrativa aceptada por la modernización neoliberal en la época de la globalización. 
BiBLIOGRAFÍA

Borde, Raymond and Chaumeton, Étienne. "Towards a Definition of Film Noir". Film Noir Reader. Alain Silver y James Ursini, eds. Nueva York: Limelinght Editions, 1999. 17-27.

Christianson, Scott R. "A Heap of Broken Images: Hardboiled Detective Fiction and the Discourse(s) of Modernity". The Cunning Craft: Original Essays on Detective Fiction and Contemporary Literary Theory. Ronald G. Walker y June M. Frazer, eds. Macomb, IL: Yeast Printing, Inc., 1990. 135-48.

Denning, Michael. Mechanic Accents: Dime Novels and Working-Class Culture in America. Londres y Nueva York: Verso, 1987.

Durgnat, Raymond. "Paint It Black: The Family Tree of the Film Noir”. Film Noir Reader. Alain Silver y James Ursini, eds. Nueva York: Limelinght Editions, 1999. 37-51.

Horsley, Lee. The Noir Thrillers. Nueva York: Palgrave, 2001.

Jameson, Fredric. The Political Unconscious: Narrative as a Socially Symbolic Act. Ithaca, NY: Cornell UP, 1981.

Malzberg, Barry N. y Don Yates. The Big Bookof Noir.Godmarn Edward, Lee Server y Martin H. Greenberg, eds. Nueva York: Carroll \& Graft, 1998. 163-170.

Mertz, Stephen. "In defense of Carroll John Daly". <www.blackmaskmagazine. com/carroldaly.html>

Nevins, Francis. First you Dream Then you Die. Mysterious Press, 1988.

O’Brien, Geoffrey. Hardboiled America: Lurid Paperbacks and Masters of Noir. Nueva York: Da Capo Press, 1997.

Rubin, Martin. Thrillers. Cambridge: Cambridge UP, 1999.

Schrader, Paul. "Notes on Film Noir". Film Noir Reader. Alain Silver y James Ursini, eds. New York: Limelinght Editions, 1999. 53-64.

Silver, Alain y James Ursini, eds. Film Noir Reader. Nueva York: Linelight Editions, 1999.

Smith, Erin A. Hard-boiled: Workin-Class Readers and Pulp Magazines. Philadelphia: U of Temple P, 2000.

Telotte, J.P. Voices in the Dark: The Narrative Patterns of Film Noir. Urbana y Chicago: The U of Illinois P, 1989.

Revista Iberoamericana, Vol. LXXVI, Núm. 231, Abril-Junio 2010, 293-303
ISSN 2154-4794 (Electrónico) 
